\title{
An electrochemical immunosensor for aflatoxin M1 determination in milk using screen-printed electrodes
}

\author{
L. Micheli*, R. Grecco, M. Badea, D. Moscone, G. Palleschi \\ Dipartimento di Scienze e Tecnologie Chimiche, Università di Roma Tor Vergata, Via della Ricerca Scientifica, 00133 Roma, Italy
}

Received 16 November 2004; received in revised form 17 December 2004; accepted 20 December 2004

Available online 2 February 2005

\begin{abstract}
The production and assembling of disposable electrochemical AFM1 immunosensors, which can combine the high selectivity of immunoanalysis with the ease of the electrochemical probes, has been carried out. Firstly immunoassay parameters such as amounts of antibody and labelled antigen, buffer and $\mathrm{pH}$, length of time and temperature of each steps (precoating, coating, binding and competition steps) were evaluated and optimised in order to set up a spectrophotometric enzyme-linked immunosorbent assay (ELISA) procedure. This assay exhibited a working range between 30 and $160 \mathrm{ppt}$ in a direct competitive format. Then electrochemical immunosensors were fabricated by immobilising the antibodies directly on the surface of screen-printed electrodes (SPEs), and allowing the competition to occur between free AFM1 and that conjugated with peroxidase (HRP) enzyme. The electrochemical technique chosen was the chronoamperometry, performed at $-100 \mathrm{mV}$. Furthermore, studies of interference and matrix effects have been performed to evaluate the suitability of the developed immunosensors for the analysis of aflatoxin M1 directly in milk. Results have shown that using screen-printed electrodes aflatoxin M1 can be measured with a detection limit of $25 \mathrm{ppt}$ and with a working range between 30 and $160 \mathrm{ppt}$. A comparison between the spectrophotometric and electrochemical procedure showed that a better detection limit and shorter analysis time could be achieved using electrochemical detection.
\end{abstract}

(C) 2004 Elsevier B.V. All rights reserved.

Keywords: Milk; Aflatoxin; Screen-printed electrode; Immunoassay

\section{Introduction}

Milk is usually contaminated with small amounts of aflatoxin M1 (AFM1) as a consequence of the metabolism by the cow of aflatoxin B1 (AFB1), a mycotoxin that is commonly produced by the fungal strains Aspergillus flavus and Aspergillus parasiticus (Scott, 1995; Miraglia, 1998) and found in certain animal foodstuff. Toxicological concern about AFM1 arises principally from its close structural similarity to AFB1, the latter having been shown to be one of the most potent known carcinogens (right insert of Figs. 2 and 4).

European Community legislation (Commission of the European Communities, 1983) limits the concentration of AFB1 in foodstuffs for dairy cows $(10 \mu \mathrm{g} / \mathrm{kg}$ in supplementary food-

\footnotetext{
* Corresponding author. Tel.: +3906 72594420; fax: +39 0672594328 .

E-mail address: laura.micheli@uniroma2.it (L. Micheli).
}

stuffs). This limit was chosen taking into account the quantities of feed consumed and the fact that $1-4 \%$ of the ingested AFB1 appears as AFM1 in the milk. The maximum allowed content of AFM1 in milk under EU directives is $0.05 \mathrm{ppb}$ $(\mu \mathrm{g} / \mathrm{kg})$ (Rosner, 1998).

AFM1 is usually determined in dairy products using methods based either on thin layer chromatography (TLC) or high performance liquid chromatography (HPLC) (Cole, 1986; Sydenham and Shephard, 1996) after extraction and clean up procedures. Detection and quantification rely on the strongly fluorescent response of the compound when irradiated by UV-light (Vasilikotis and Papadoyannis, 1985; Bijl and van Peteghem, 1985). In general, these measurement techniques require three steps: extraction to remove the aflatoxin from complex mixtures of materials in which it is found, purification to remove interferents, and finally detection and quantification. These methods are sufficiently sensitive and accurate, 
but they are not suitable for the screening of large numbers of samples.

Immunochemical recognition of analytes has been explored in two different ways to improve analysis of aflatoxin. Some more modern methods of sample extraction (Gilbert, 2002; Scott, 1989) utilise aflatoxin specific antibodies to efficiently extract and purify aflatoxin from complex mixtures. Immunoassay techniques, which are based on the ability of the antibodies to form complexes with corresponding antigens, have been successfully applied for the assay of aflatoxins since the property of highly specific molecular recognition of antigens by antibodies leads to highly selective assays. The extremely high affinity of antigen-antibody interactions also provides in the very high sensitivity. This allows sensitive, cost-effective, and practical screening analysis to be devised. There are currently a number of immunochemically based assays that are used for detecting this toxin (Chu, 1990; Carlson et al., 2000; Amine et al., 2003): radioimmunoassay (RIA), enzyme-linked immunosorbent assay (ELISA), immunoaffinity column assay (ICA) and immunoaffinity fluorimetric biosensor (APL sensor). At present, AFM1 analysis is carried out using ELISA kits for screening AFM1 and AFB1 (Baincardi, 1997), with confirmation by HPLC (which is the official method) using post column derivatisation after sample clean up (Markaki and Melissari, 1997).

While immunochemical techniques require relatively little equipment, few materials and little maintenance of laboratory instrumentations, they are still labour intensive. Our intention is to develop a disposable immunosensor for aflatoxin M1. It could be used for detection of toxin in milk and would combine the high selectivity of immunoanalysis with the convenience of electrochemical probes. An amperometric immunosensor for the determination of AFM1 in milk has, in fact, been constructed and based on a screen-printed electrode (SPE). Spectrophotometric ELISA was used as a development tool prior to transfer of the AFM1 assay onto SPEs. The resulting assay is performed in a direct competitive scheme (insert of Figs. 2 and 4). A monoclonal antibody (MAb) produced against this toxin, was immobilised on the support. After the competition step, the amount of AFM1-HRP conjugate that reacted with the immobilised MAb was evaluated after the addition of the enzymatic substrate, $3,3^{\prime}, 5,5^{\prime}-$ tetramethylbenzidine dihydrochloride (TMB). The electroactive product was detected by use of chronoamperometry, performed at an applied potential of $-100 \mathrm{mV}$, at which the TMB product undergoes reduction.

\section{Experimental}

\subsection{Materials and reagents}

Polystyrene microtitre plates, MaxiSorp ${ }^{\mathrm{TM}}$, were purchased from NUNC ${ }^{\mathrm{TM}}$ (Roskilde, Denmark). Aflatotoxin M1 (AFM1) was purchased from Alexis Biochemicals (Carlsbad, CA, USA). Milk samples were obtained from local su- permarkets. Ridascreen AFM1 KIT with aflatoxin M1 labelled with Peroxidase (AFM1-HRP) was purchased from R-Biopharm (Darmstadt, Germany). The monoclonal antibodies against AFM1 (MAb) were purchased from Maine Biotechnology Services (USA). Polyvinyl alcohol (PVA), 3,3',5,5'-tetramethylbenzidine dihydrochloride (TMB) and all other reagents were from Sigma (St. Louis, MO, USA). The BCR reference material containing aflatoxin M1 (CRM 283) was purchased from the Institute for Reference Materials and Measurements (IRMM, Belgium). Affinity purified anti-mouse $\operatorname{IgG}(\mathrm{H}+\mathrm{L})$ from goat were purchased from Vector Laboratories Inc. (Burlingame, CA, USA).

Screen-printed electrodes (SPEs), consisting of a graphite working and counter electrode, and a silver reference electrode, were obtained from EcoBioService and Research (Florence, Italy).

\subsection{Apparatus}

A model 550 microplate reader (Bio-Rad) was used to read the absorbance on ELISA plates at $655 \mathrm{~nm}$. All electrochemical measurements were performed using a computercontrolled system, AUTOLAB model PGSTAT 12 with GPES software (ECO-CHEMIE, The Netherlands).

\subsection{Buffer solutions}

A 100 and $50 \mathrm{mM}$ carbonate buffers (CB), pH 9.6, were used for the immobilisation of the anti-mouse IgG on both microplates and electrodes, respectively. Phosphate saline buffer (PBS, $15 \mathrm{mM}$ ), pH 7.4 was used for the coating (immobilisation of MAb) and competition steps. Polyvinyl alcohol (PVA) solution 1\% (w/v) in PBS was used as blocking reagent. The washing solutions, used after each assay step, were prepared by adding $0.05 \%$ Tween $20(\mathrm{v} / \mathrm{v})$ to the PBS (PBS-T).

\subsection{Procedure for spectrophotometric ELISA}

Assay parameters are characterised by competitive enzyme immunoassays (ELISA) in microplates. Spectrophotometric detection was optimised during the development phase prior to analysis by SPE. A direct ELISA was performed by coating the microplate with anti-mouse $\operatorname{IgG}(10 \mu \mathrm{g} / \mathrm{mL}$, $50 \mu \mathrm{L} /$ well) in $100 \mathrm{mM} \mathrm{CB}, \mathrm{pH} 9.6$, overnight at $4{ }^{\circ} \mathrm{C}$ (precoating step). After a washing step with PBS-T (two times, $200 \mu \mathrm{L}$ ) followed by PBS alone (one time, $200 \mu \mathrm{L}$ ), the blocking reagent (1\% PVA in PBS) was added to the wells and left for $1 \mathrm{~h}$ at $37^{\circ} \mathrm{C}$. The wells were then washed again. For the coating step, $10 \mu \mathrm{g} / \mathrm{mL}$ of a solution of monoclonal antibody against AFM1 (MAb) were incubated into the microplate wells for $2 \mathrm{~h}$ at $37^{\circ} \mathrm{C}$. After a washing step, the competitive procedure was carried out as follows: different dilutions of free toxin (standard or sample) were incubated in the wells for $10 \mathrm{~min}$ at room temperature before the addition of a fixed concentration of AFM1-HRP (1:30, v/v) in PBS. 
The reaction was allowed to proceed for $2 \mathrm{~h}$ at room temperature and the microtitre plate was then rinsed with PBS-T. The chromogen/substrate solution was added into the wells, the reaction proceeded for $30 \mathrm{~min}$ at room temperature, and finally the absorbance was read at $655 \mathrm{~nm}$.

Each experiment was performed in triplicate and the mean of each value was used for curve fitting.

\subsection{Procedure for electrochemical immunosensor}

The working electrode of the SPE was coated with $8 \mu \mathrm{L}$ of $10 \mu \mathrm{g} / \mathrm{mL}$ Anti-IgG (mouse) solution in $50 \mathrm{mM}$ carbonate buffer $\mathrm{pH} 9.6$ overnight at $4{ }^{\circ} \mathrm{C}$. After rinsing with $50 \mu \mathrm{L}$ of PBS-T (PBS + 0.05\% Tween 20), the SPE was incubated with $8 \mu \mathrm{L}$ of the blocking solution (1\% PVA in PBS) for $30 \mathrm{~min}$ at room temperature. After another washing step, $6 \mu \mathrm{L}$ of primary antibody $(20 \mu \mathrm{g} / \mathrm{mL}$ of monoclonal anti-AFM1 in PBS) were added to the working electrode. The competition step was carried out as follow: several AFM1 standard solutions were left to react on the SPE for 25 min and then mixed with the AFM1-HRP conjugate at constant concentration (1:20, $\mathrm{v} / \mathrm{v})$. The competition reaction was allowed to proceed to dryness at room temperature in the dark. The electrodes were then rinsed with PBS-T and, finally the chromogen/substrate solution was dropped onto the electrode surface ( $70 \mu \mathrm{L} / \mathrm{SPE})$. The enzymatic reaction was stopped after $25 \mathrm{~min}$ at room temperature and the current was sampled at $1 \mathrm{~s}$.

\subsection{Analysis of sample}

The determination of AFM1 in milk was carried out by spiking a milk sample (before or after centrifugation), to study any matrix effect and the percentage recovery.

The preparation of the sample consisted to centrifugation for defatting for $15 \mathrm{~min}$ at $6000 \mathrm{rpm}$. After centrifugation the phases were completely separated into layers of fat, cream and skimmed milk from top to bottom, respectively. The defatted sample was recovered and tested directly.

\subsection{Calibration curves for spectrophotometric ELISA and immunosensor}

Standard curves were obtained using AFM1 standard solutions $(0-720 \mathrm{pg} / \mathrm{mL})$ prepared in PBS for spectrophotometric ELISA and electrochemical immunosensor.

For the competitive assay, the matrix effect of blank samples on both assays was evaluated. The centrifuged milk blank was fortified with AFM1 standard solutions $(8-960 \mathrm{pg} / \mathrm{mL}$ ) and used directly on microplates and SPEs.

Calibration curves in fortified milk, prepared by the AFM1 standard solutions before the centrifugation $(30-720 \mathrm{pg} / \mathrm{mL}$ ) were subjected to spectrophotometric and electrochemical ELISA to study the effect of any loss of sample after centrifugation.

Each experiment was performed in triplicate and the mean of each value was used for curve fitting. The calibration curves (absorbance at $655 \mathrm{~nm}$ or current versus competitor concentration) were fitted using "non-linear four parameter logistic calibration plots" (Warwick, 1996). The four parameter logistic function is:

$f(x)=\left\{\frac{[1-a]}{\left[1+(x / c)^{b}\right]}\right\}+d$

where parameters $a$ and $d$ are the asymptotic maximum and minimum values, respectively; $c$ is the value at the inflection point $\left(\mathrm{IC}_{50}\right)$ and $b$ is the slope.

To allow the direct comparison of calibration curves, absorbance values were converted into their corresponding test inhibition values $\left(\% A / A_{0}\right)$ as follow:

$\% \frac{A}{A_{0}}=100 \times \frac{A-A_{\text {sat }}}{A_{0}-A_{\text {sat }}}$

where $A$ is the absorbance value of competitors, $A_{\text {sat }}$ and $A_{0}$ are the absorbance values corresponding to the saturating and the non-competition analyte, respectively (as evaluated by the four parameters logistic function).

The detection limit (LOD) was defined as the concentration of AFM1 equivalent to three times the value of the standard deviation $(s)$, measured in the absence of AFM1 ( $A_{0}$, no competition point). The midpoint value $\left(\mathrm{IC}_{50}\right)$ was evaluated as the concentration of AFM1 at $50 \% A / A_{0}$. The working range was evaluated as the toxin concentration that gives test inhibition values of 90 and $10 \%$ of $A / A_{0}$ (Giraudi et al., 1999).

The data obtained for each curve were plotted and fitted using a SigmaPlot software (SPSS), and a regression analysis on the linear portion of the sigmoidal curves was also performed. The slopes obtained from the regression analysis were used to evaluate the matrix effects and the recovery of the assay.

In addition, a reference material (CRM 283, aflatoxin M1 in whole milk powder $0.09 \mu \mathrm{g} / \mathrm{mL}$ ) supplied by the IRMM (Belgium) was analysed. Each experiment was performed in six replicates and mean values were used for curve fitting.

\section{Results}

\subsection{Optimisation of spectrophotometric ELISA parameters}

The development of the spectrophotometric ELISA for AFM1 before proceeding to the electrochemical study allowed the definition of the working ranges, limit of detection and the characteristics of the immunological reagents (antigen and antibody) prior to the evaluation of the system on an electrode. The tests were performed in a 96-well microplate according to a direct ELISA format. This kind of test is based on a competition between added antigen labelled with the enzyme and unlabelled (sample or standard) for the binding sites of antibodies immobilised on the preactivated support (insert in Figs. 2 and 4). The preacti- 
vation consists of an immobilisation (precoating) of antiIgG antibody (mouse), which improves both the amount, and the orientation of the antibody specific for the analyte to be measured. At the conclusion of the chain of immunological reaction, the amount of label associated with the solid phase is inversely related to the concentration of antigen.

The first step in assay development was the selection of the buffer (carbonate and phosphate saline buffers), the time (overnight and $2 \mathrm{~h}$ ), the temperature $\left(37,4{ }^{\circ} \mathrm{C}\right.$ and room temperature) and the concentration of the precoating (antibody against $\operatorname{IgG}$ ) and coating (monoclonal antibody against AFM1-MAb) used in the various steps. Results showed that the best assay conditions were achieved when $10 \mu \mathrm{g} / \mathrm{mL}$ of anti-IgG was incubated overnight at $4{ }^{\circ} \mathrm{C}$ in $\mathrm{CB}$ in the precoating step and $10 \mu \mathrm{g} / \mathrm{mL}$ of primary monoclonal antibody (MAb) in PBS for $2 \mathrm{~h}$ at $37^{\circ} \mathrm{C}$ was used in the coating step (Fig. 1a and b). In particular, the results of the coating incubation time showed that there was no difference between
$2 \mathrm{~h}$ and overnight incubation time, and thus the shorter time could be used.

The binding study was carried out by adding several dilutions of AFM1-HRP conjugate into the microplate wells. The $80 \%$ value for the response curve defines the amount of labelled antigen to be used in the competition study in order to obtain the highest sensitivity (Warwick, 1996). From the results, shown in Fig. 1c the 1:30 (v/v) dilution of the conjugate was chosen.

The competition study was carried out setting up two protocols: in the first one, free and labelled AFM1 were mixed together directly on the support where the specific antibody was immobilised. In the second protocol, different dilutions of free toxin were added onto the support before the addition of the labelled antigen. In this second case we tried to promote the binding of the AFM1 with its antibody, in order to increase the sensitivity of the analysis. Different incubation times $(10,30,60 \mathrm{~min})$ of the free antigen were studied and the best results were obtained with the antigen added $10 \mathrm{~min}$ be-
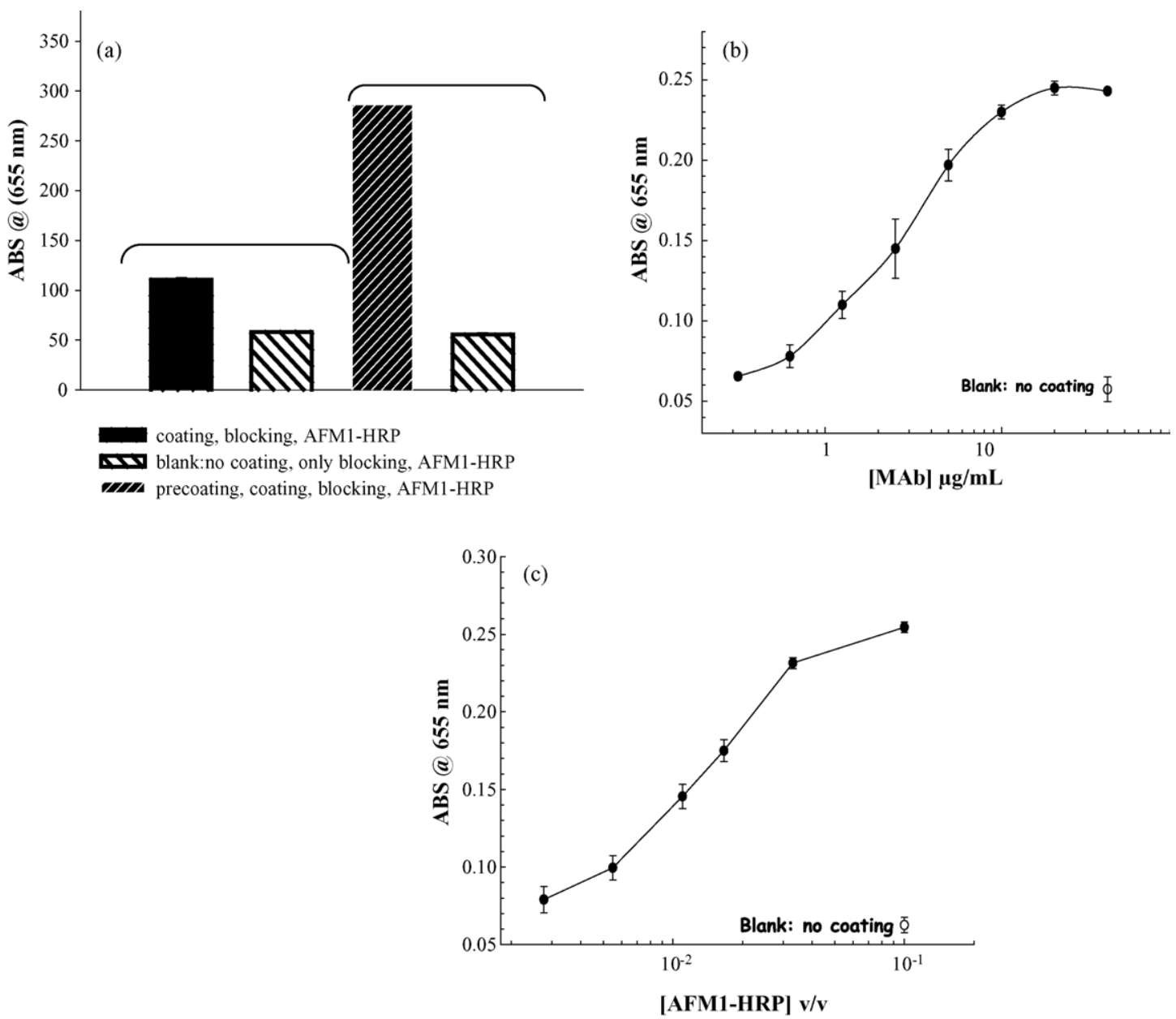

Fig. 1. (a) Precoating study: comparison between the results obtained with (ם) and without $(\mathbf{\Phi})$ immobilisation of antibody against $\mathrm{IgG}(10 \mu \mathrm{g} / \mathrm{mL})$ in order to improve the assay through better orientation and coverage of primary antibody. (b) Coating study: coating curve obtained by the incubation of increasing concentration of anti-AFM1 antibody (MAb) for $2 \mathrm{~h}$ at $37^{\circ} \mathrm{C}$. Fixed amounts of anti-IgG antibody and AFM1 labelled with enzyme (AFM1-HRP) were used. (c) Binding study: the binding curve obtained with the incubation of decreasing dilution of labelled toxin (AFM1-HRP) for $2 \mathrm{~h}$ at room temperature. Fixed amounts of anti-IgG antibody $(10 \mu \mathrm{g} / \mathrm{mL})$ and $\mathrm{MAb}(10 \mu \mathrm{g} / \mathrm{mL})$ were used. Absorbance was read at $655 \mathrm{~nm}$; chromogen/substrate of $\mathrm{HRP}: \mathrm{TMB} 0.2 \mathrm{mM}+\mathrm{H}_{2} \mathrm{O}_{2} 1 \mathrm{mM}$, in citrate-phosphate buffer $\mathrm{pH}$ 5.2. 
fore the labelled AFM1 (data not shown). For both protocols the total competition time was $2 \mathrm{~h}$.

Calibration curves (absorbance at $655 \mathrm{~nm}$ versus competitor concentration) were obtained using AFM1 standard solutions prepared in PBS $(0-480 \mathrm{pg} / \mathrm{mL})$ and were fitted using "non-linear four parameter logistic calibration plots" (Warwick, 1996).

Different working ranges resulted for the two protocols:

- in the first protocol, the working range was $0.2-7.4 \mathrm{ng} / \mathrm{mL}$ (ppb) and the LOD was $0.1 \mathrm{ng} / \mathrm{mL}$;

- in the second one, with $10 \mathrm{~min}$ of free AFM1 incubation time, it was $30-160 \mathrm{pg} / \mathrm{mL}$ (ppt) and the LOD was $25 \mathrm{pg} / \mathrm{mL}$.

Only in the second case was the regulatory limit $(50 \mathrm{ppt})$ of AFM1 detectable (Fig. 2).

\subsection{Optimisation of electrochemical ELISA parameters}

For the detection of AFM1 by electrochemical ELISA, an amperometric immunosensor was assembled using a screenprinted electrode (SPE) coated with a monoclonal antibody and a direct competitive assay format as for the developed spectrophotometric procedure. The reagents were added in small volumes.

The electrochemical technique chosen for the detection of the enzymatic activity was chronoamperometry, which was performed at a potential of $-100 \mathrm{mV}$ where the TMB product undergoes reduction.

As for the spectrophotometric study, immunoassay parameters such as the amount of antibody (anti-IgG and MAb) and labelled antigen, buffer and $\mathrm{pH}$, length of time and temperature of each step were evaluated and optimised.

Fig. 3a and $b$ represents the results obtained with the coating and binding study. The optimised concentrations of the specific antibody for AFM1 and for the AFM1-HRP conjugate employed in order to have the maximum response from the competitive study were: $20 \mu \mathrm{g} / \mathrm{mL}$ for the antibody anti-AFM1 and 1:20 (v/v) for AFM1-HRP, respectively. The competition study was carried out by setting up two protocols as for the spectrophotometric assay. The total time of the competition steps in each case was $50 \mathrm{~min}$.

Standard curves (current versus competitor concentration) were obtained using AFM1 standard solutions

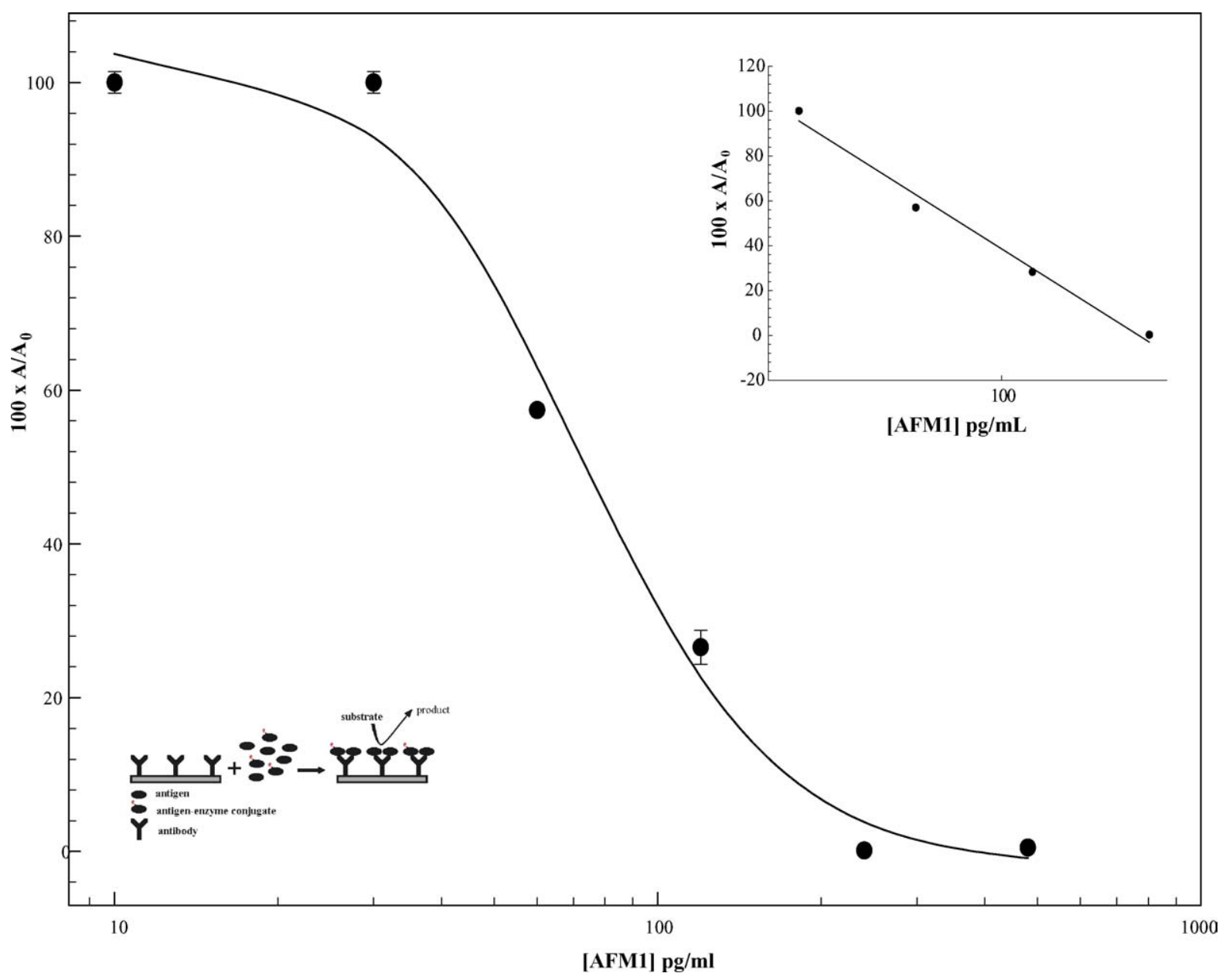

Fig. 2. Spectrophotometric competitive ELISA for aflatoxin M1 adding the free toxin 10 min before the AFM1-HRP conjugate. Anti-IgG antibody (10 $\mu \mathrm{g} / \mathrm{mL})$ and $\mathrm{MAb}(10 \mu \mathrm{g} / \mathrm{mL})$ were coated on the ELISA plate. Linear regression shows a working range of $30-240 \mathrm{pg} / \mathrm{mL}\left(r^{2}=0.987\right)$, as in the top right insert. 

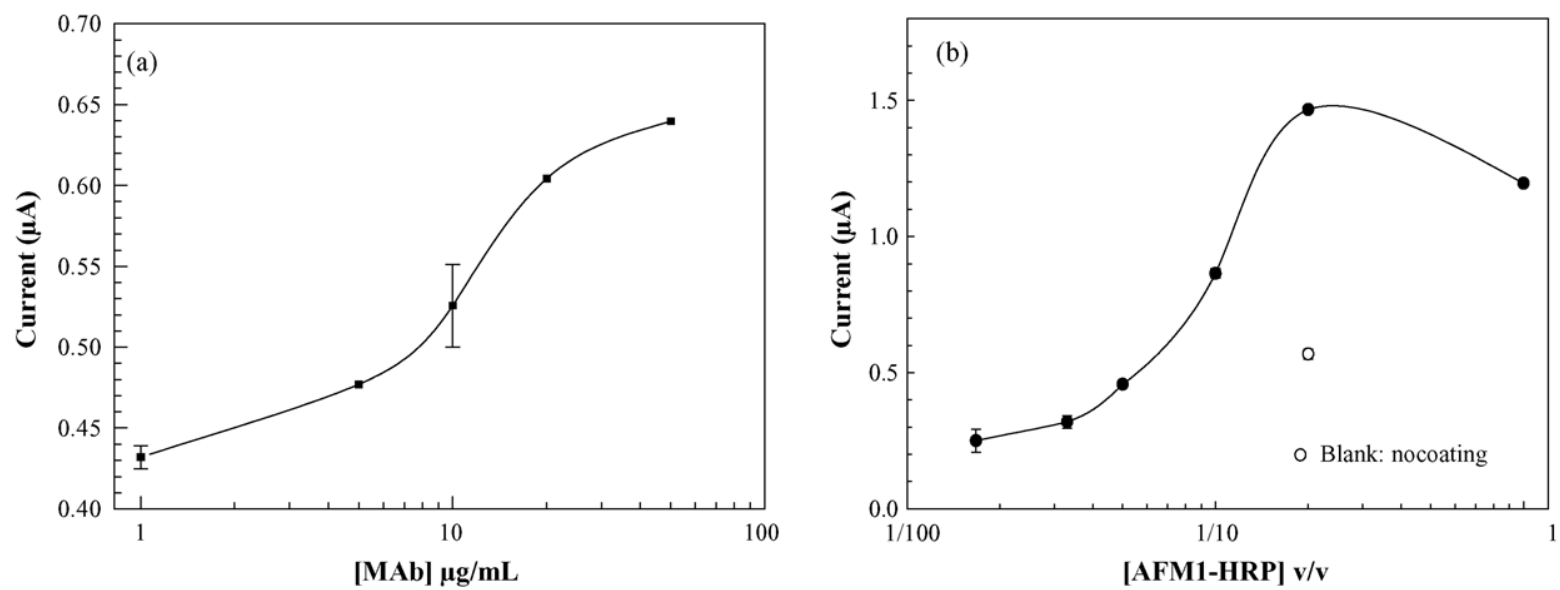

Fig. 3. (a) Coating study: coating curve obtained with the incubation of increasing concentration of anti-AFM1 antibody (MAb), until dryness at RT. Fixed amounts of anti-IgG antibody $(1: 10 \mu \mathrm{g} / \mathrm{mL})$ and AFM1 labelled with enzyme (AFM1-HRP) (1:20, v/v) were used. (b) Binding study: binding curve obtained with the incubation of decreasing dilution of labelled toxin (AFM1-HRP) for $50 \mathrm{~min}$ at room temperature. Fixed amounts of anti-IgG antibody (10 $\mu \mathrm{g} / \mathrm{mL}$ ) and MAb $(20 \mu \mathrm{g} / \mathrm{mL})$ were used. Electrochemical technique: chronoamperometry, applied potential: $-100 \mathrm{mV}$; chromogen/substrate of HRP: substrate TMB $0.2 \mathrm{mM}+\mathrm{H}_{2} \mathrm{O}_{2} 1 \mathrm{mM}$, in citrate-phosphate buffer $\mathrm{pH} 5.2$.

$(0-720 \mathrm{pg} / \mathrm{mL})$ prepared in PBS and were fitted using "nonlinear four parameter logistic calibration plots" (Warwick, 1996). Also for the electrochemical system, different times $(0,10,30,60 \mathrm{~min})$ of the incubation of free antigen were studied and the best results were obtained when the antigen was added 25 min before the labelled AFM1.

The results obtained for the addition of both free AFM1 and AFM1-HRP on the support showed also in this case a different working range for the two protocols:

- in the first case (Fig. 4a), the working ranges was $1-10 \mathrm{ng} / \mathrm{mL}$ (ppb) and the LOD was $0.5 \mathrm{ng} / \mathrm{mL}$;

- in the second case (Fig. 4b), with 10 min of free AFM1 pre-incubation time, the working range was $30-220 \mathrm{pg} / \mathrm{mL}$ (ppt) and LOD was $25 \mathrm{pg} / \mathrm{mL}$.

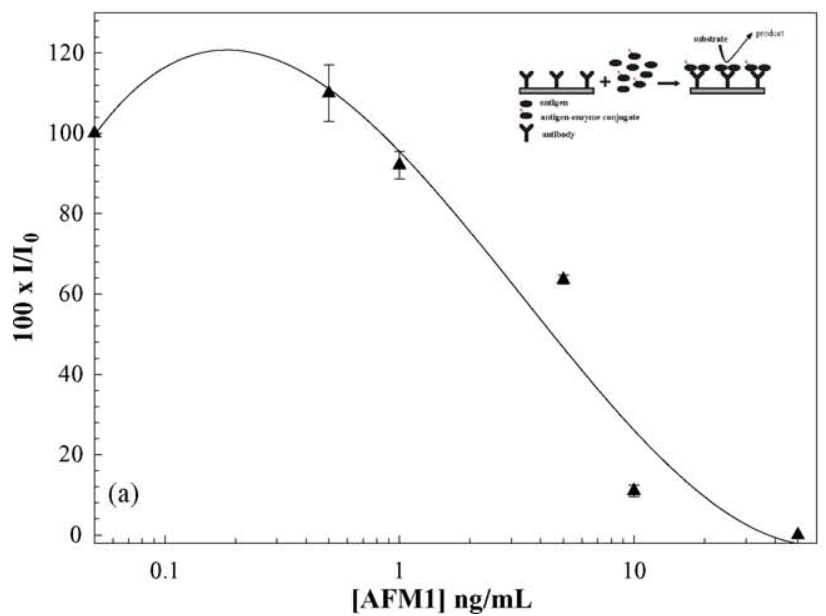

As with the spectrophotometric assay, only in the second protocol met the requirements of $\mathrm{EU}$ (up to $50 \mathrm{pg} / \mathrm{mL}$ ).

\subsection{Sample analysis}

The determination of AFM1 in milk has been carried out with spiked samples (toxin added before or after centrifugation), in order to determine the matrix effect and the recovery. The sample preparation consisted in centrifugation for $15 \mathrm{~min}$ at $6000 \mathrm{rpm}$ for defatting milk. After the centrifugation, the two phases were completely separated into two layers of fatty cream and skimmed milk from top to bottom, respectively. The defatted milk was recovered and tested directly.

A preliminary study for the electrochemical determination of AFM1 in milk involved the electrochemical charac-

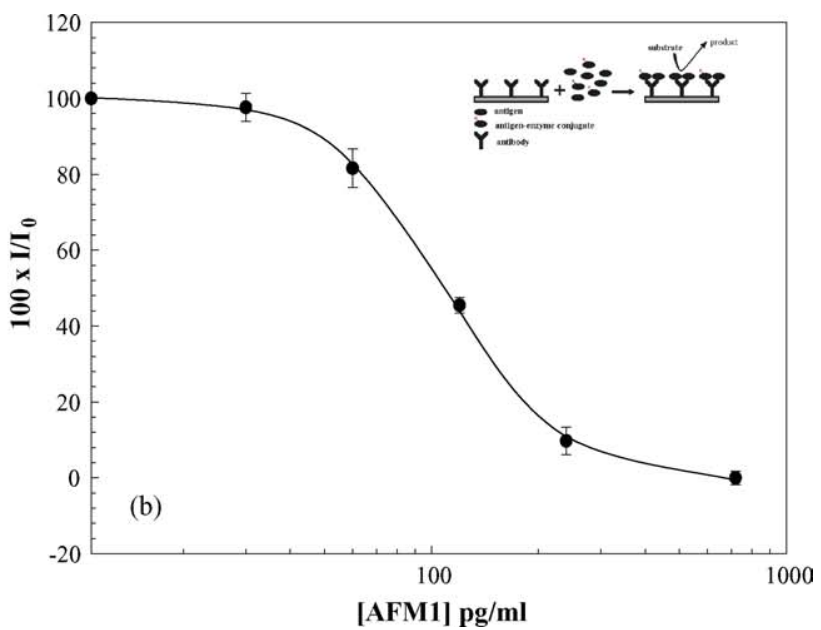

Fig. 4. Electrochemical competitive ELISA: (a) competition curve obtained for direct mixing of free and labelled AFM1 on the working electrode of SPE; (b) competition curve generated by adding the free toxin $25 \mathrm{~min}$ before the AFM1-HRP conjugate. Anti-IgG antibody $(10 \mu \mathrm{g} / \mathrm{mL}) \mathrm{and} \mathrm{MAb}(20 \mu \mathrm{g} / \mathrm{mL})$ were coated on the working electrode of the SPE. Linear regression shows a working range of $0.5-10 \mathrm{ng} / \mathrm{mL}\left(r^{2}=0.964\right)$ for $\left(\right.$ a) and $30-220 \mathrm{pg} / \mathrm{mL}\left(r^{2}=0.966\right)$ for (b). Electrochemical technique: chronoamperometry, applied potential: $-100 \mathrm{mV}$; chromogen/substrate of HRP: substrate $\mathrm{TMB} 0.2 \mathrm{mM}+\mathrm{H}_{2} \mathrm{O}_{2} 1 \mathrm{mM}$, in citrate-phosphate buffer $\mathrm{pH}$ 5.2. 

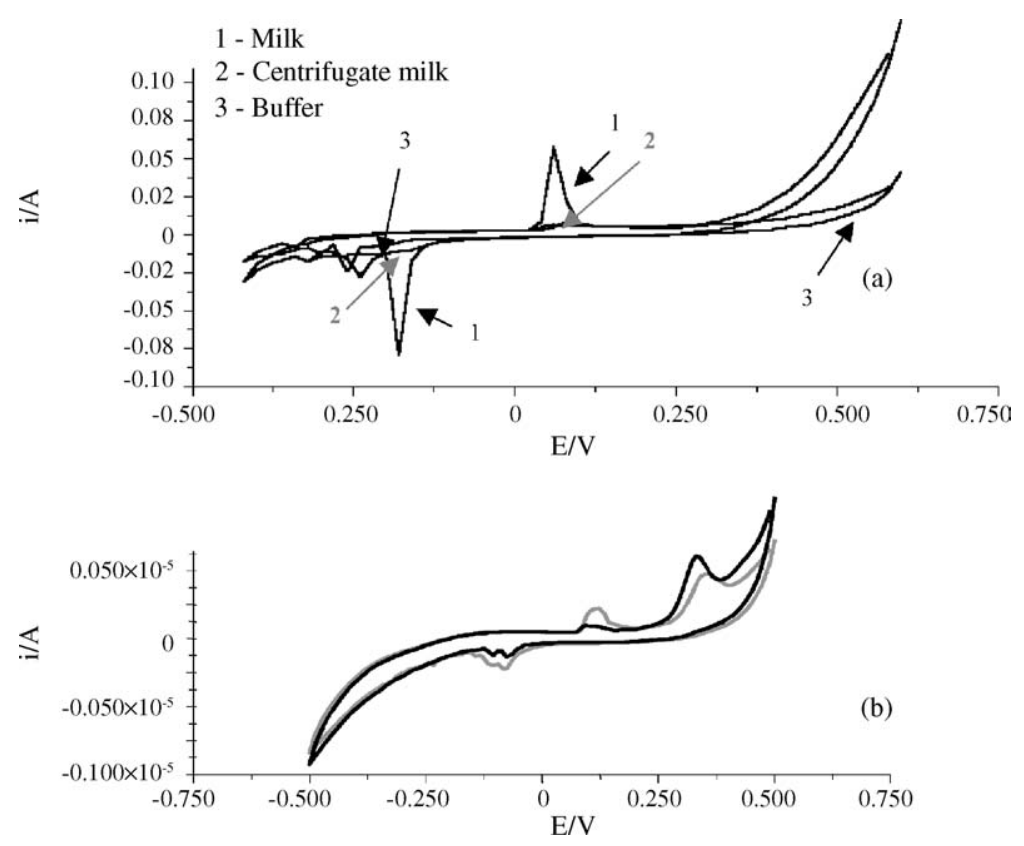

Fig. 5. (a) Cyclic voltammograms of milk on SPE for investigation of the electrochemical behaviour of whole milk: (1) whole milk; (2) centrifuged milk; (3) phosphate saline buffer (PBS) pH 7.4. (b) Cyclic voltammograms of TMB-ox before (pale grey) and after (black) 30 min incubation in milk.

terisation of the enzymatic product in the presence of the milk in order to evaluate the matrix effect. Fig. 5a shows the cyclic voltammograms obtained with buffer, milk and centrifuged milk demonstrating that there was an electrochemical response in milk that disappeared when it was centrifuged. Fig. $5 \mathrm{~b}$ shows the results obtained with the TMB-ox product before and after $30 \mathrm{~min}$ of incubation of milk onto the working electrode to mimic the competitive assay condition. These data show that there was not a significant interference from the compounds present in milk on the electrochemical response of the enzymatic product.

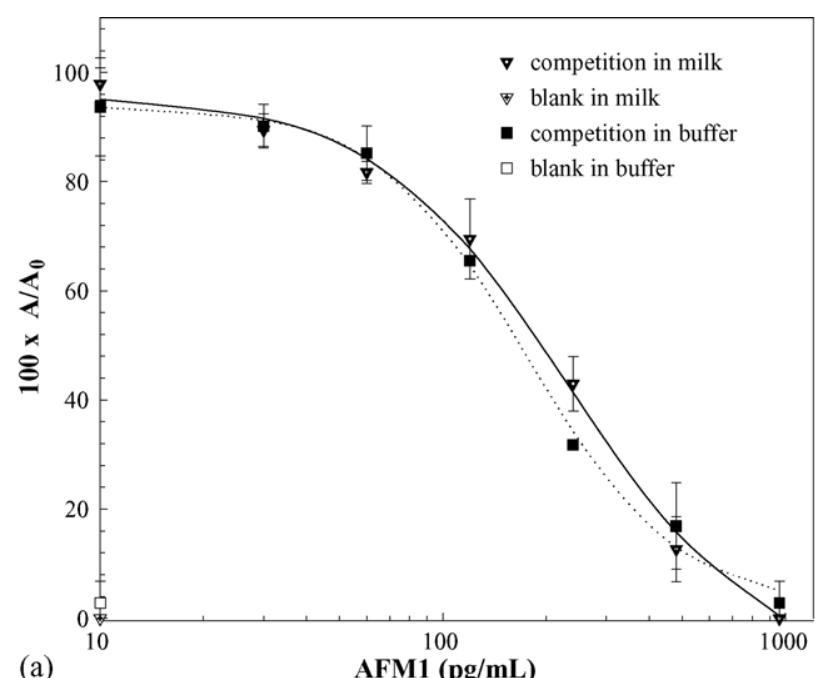

The matrix effect of milk on both ELISA systems was tested using commercial whole milk, where AFM1 was not present (milk blank). Centrifuged milk blanks were then fortified with AFM1 standard solutions $(8-960 \mathrm{pg} / \mathrm{mL})$ and used directly in the assay (Fig. 6a and b).

The spectrophotometric and electrochemical results showed a good working range (larger for the spectrophotometric assay), comparable to the ones obtained in buffer, and thus it is possible to measure the analyte directly in milk, without dilution or pretreatment. The possibility of working without a sample dilution is important considering the low

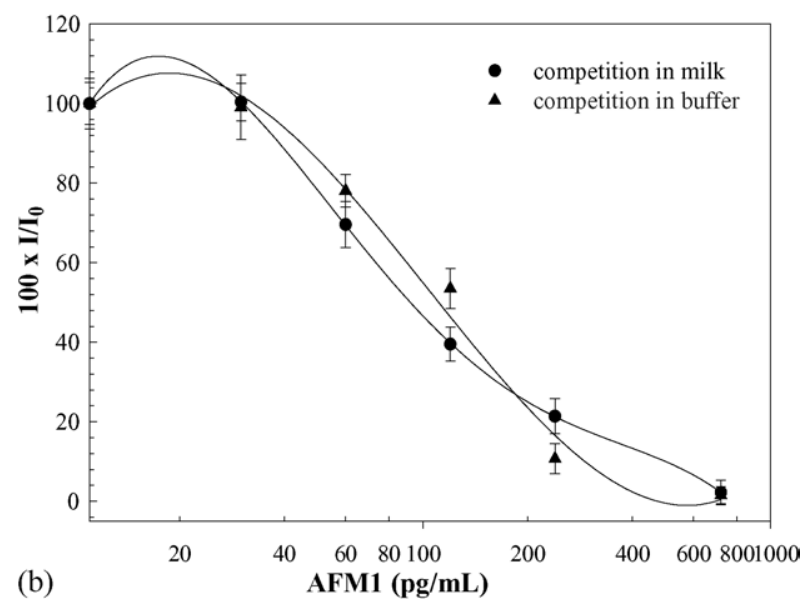

Fig. 6. Matrix effect: comparison between competition curve in buffer ( $\mathbf{\square})$ and competition curve in milk ( $\mathbf{\nabla})$ without dilution. Chromogen/substrate of HRP: substrate TMB $0.2 \mathrm{mM}+\mathrm{H}_{2} \mathrm{O}_{2} 1 \mathrm{mM}$, in citrate-phosphate buffer $\mathrm{pH}$ 5.2. (a) Spectrophotometric detection: absorbance read at $655 \mathrm{~nm}$; (b) electrochemical detection: chronoamperometry, applied potential: $-100 \mathrm{mV}$. 
Table 1

Extraction efficiency obtained for the spectrophotometric and electrochemical systems using the same fortified samples (AFM1 standard solutions added before the extraction)

\begin{tabular}{|c|c|c|c|c|c|c|c|c|}
\hline \multirow[t]{2}{*}{ AFM1 added (pg/ml) } & \multicolumn{4}{|c|}{ Spectrophotometric ELISA } & \multicolumn{4}{|c|}{ Electrochemical ELISA } \\
\hline & $\begin{array}{l}\text { AFM1 found } \\
(\mathrm{pg} / \mathrm{ml})\end{array}$ & $\begin{array}{l}\% \text { R.S.D. } \\
(n=6)\end{array}$ & $\% \mathrm{RE}$ & $\%$ Recovery & $\begin{array}{l}\text { AFM1 found } \\
(\mathrm{pg} / \mathrm{ml})\end{array}$ & $\begin{array}{l}\% \text { R.S.D. } \\
(n=6)\end{array}$ & $\%$ Recovery & $\% \mathrm{RE}^{\mathrm{a}}$ \\
\hline 30 & 26 & 5 & -13 & 87 & 27 & 4 & 90 & -10 \\
\hline 60 & 55 & 7 & -8 & 92 & 55 & 6 & 92 & -8 \\
\hline 240 & 225 & 5 & -6 & 94 & 230 & 6 & 97 & -4 \\
\hline 720 & 706 & 4 & -2 & 98 & 720 & 8 & 100 & 0 \\
\hline 90 (certified material) & 89 & 5 & -1 & 99 & 91 & 8 & 101 & 1 \\
\hline
\end{tabular}

a $\% \operatorname{RE}(\%$ relative error $)=[($ measured value - true value $) /$ true value $] \times 100$.

toxin concentration in milk. In comparing the electrochemical and spectrophotometric assays, it can be noted that for the spectrophotometric assay, spiked centrifuged milk needed to be added $60 \mathrm{~min}$ before the conjugated toxin in order to obtain comparable results with that obtained in buffer (addition of AFM1 10 min before the labelled toxin), while for the electrochemical system the same competition protocol could be used in both cases, milk or buffer. The time for each measurement with the electrochemical system was shorter than the spectrophotometric assay: $75 \mathrm{~min}$ versus $150 \mathrm{~min}$. The detection limits, for both systems, were lower than the maximum permissible level of aflatoxin in milk.

The recovery was evaluated by a comparison of the calibration curves constructed (1) by spiking blank centrifuged milk samples with known amounts of AFM1 before centrifugation and (2) adding the toxin to the milk blank after the centrifugation. For each concentration level (Table 1), four different samples were independently processed and analysed using eight different SPEs. On the basis of the calibration curves prepared in centrifuged milk it was possible to calculate the recovery of the analyte (90-100\% of AFM1 added; the value of $90 \%$ is observed for the lowest concentration of the toxin). Comparable results $(99 \pm 5 \%$ of AFM1) were obtained using the reference material (CRM 283) supplied by the IRMM. To obtain samples falling within our working range, the CRM 283 material was extracted as described above. The results regarding recovery with this procedure were in agreement with those reported in the literature (van Egmond and Wagstaffe, 1992). The precision was determined by calculating the relative standard deviation (R.S.D.) for the replicate measurements and the accuracy (\%RE) was calculated by assessing the agreement between measured and nominal concentration of the fortified samples. In order to evaluate the repeatability and accuracy of the analytical method, six replicates of the CRM $283(0.09 \mu \mathrm{g} / \mathrm{kg})$ were analysed (Table 1) with satisfactory results.

\section{Conclusion}

In this work, a disposable electrochemical immunosensor for the detection of AFM1 was developed using a screen- printed electrode (SPE) system as transducer for chronoamperometry and a monoclonal antibody for molecular recognition. We took advantage of the simplicity of the ELISA system to construct an AFM1 immunosensor that was capable of measuring the same levels of toxin as detected by the conventional methods. Our system has the important advantage of allowing the measurement of AFM1 directly in milk following a simple centrifugation step but without dilution or other pretreatment steps. The sensor exhibited linearity between 30 and $240 \mathrm{ng} / \mathrm{ml}$ making it useful for AFM1 monitoring in milk (maximum acceptable level of AFM1 in milk is $50 \mathrm{ppt}$ ). Recovery of AFM1 from spiked milk was around $(95 \pm 6) \%$. For certified material (CRM 283) the recovery was around $(99 \pm 5) \%$ of AFM1.

In conclusion, we have demonstrated that a competitive immunoassay for AFM1, coupled with either electrochemical or spectrophotometric detection, is indeed a functional strategy and that the immunosensor realised for this toxin shows a working range that is comparable to that found for conventional methods and which was, in turn, suitable for "on site" monitoring. A further advantage is that the analysis time is reduced from the conventional methods (HPLC or TLC) to $75 \mathrm{~min}$.

\section{Acknowledgements}

This work was supported by financial contributions from the "ROSEPROMILK QLK1 CT 2001 01617" and "Giovani Ricercatori 2001" research projects.

\section{References}

Amine, A., Micheli, L., Moscone, D., Palleschi, G., 2003. Rapid online analysis to ensure the safety of milk. In: Smit, G. (Ed.), Dairy Processing-Improving Quality. Woodhead Publishing Limited and CRC Press, Cambridge, UK, pp. 292-309.

Baincardi, A., 1997. Determinazione di aflatossina M1 nel latte, XXXVI. Industrie Alimentari, pp. 870-876.

Bijl, J.P., van Peteghem, C., 1985. Rapid extraction and sample clean up for the fluorescence densitometric determination of aflatoxin M1 in milk and milk powder. Anal. Chim. Acta 170, 149152.

Carlson, M.A., Bargeron, C.B., Benson, R.C., Fraser, A.B., Phillips, T.E., Velky, J.T., Groopman, J.D., Strickland, P.T., Ko, H.W., 2000. An 
automated, handheld biosensor for aflatoxin. Biosen. Bioelectron. 14, 841-848.

Chu, F.S., 1990. Immunoassays for mycotoxins: current state of art, commercial and epidemiological application. Vet. Hum. Toxicol. 32 (Suppl.), 42-50.

Cole, R.J., 1986. Modern Methods in the Analysis and Structural Elucidation of Mycotoxins. Academic Press Inc., Orlando, USA.

Commission of the European Communities, 1983. Third Commission Directive of 28 July 1983 amending the annex to Council Directive 74/63/EEG on the fixing of maximum permitted levels for undesirable substances and products in feeding-stuffs. J. Eur. Commun. L222, 31-32.

Gilbert, J., 2002. Validation of analytical methods for determining mycotoxins in foodstuffs. Trends Anal. Chem. 21 (6-7), 468-486.

Giraudi, G., Rosso, I., Baggiani, C., Giovanoli, C., Vanni, A., Grassi, G., 1999. Development of enzyme linked immunosorbent assay for benalaxyl and its application to the analysis of water and wine. Anal. Chim. Acta 392, 85-94.

Markaki, P., Melissari, E., 1997. Occurrence of aflatoxin M1 in commercial pasteurised milk determined with ELISA and HPLC. Food Addit. Contam. 14 (5), 451-456.

Miraglia, M., 1998. Mycotoxins and phycotoxins-developments in chemistry, toxicology and food safety. In: Miraglia, M., van Edgmond, H.P., Bresa, C., Gilbert, J. (Eds.), Proceedings of the Inter- national IUPAC Symposium on Mycotoxin and Phycotoxin. Alaken Inc., Fort Collins, CO, USA, p. 67, 151, 181.

Rosner, H., 1998. Mycotox: limits in European Union and effect on trade. In: Miraglia, M., van Edgmond, H.P., Bresa, C., Gilbert, J. (Eds.), Proceedings of the International IUPAC Symposium on Mycotoxin and Phycotoxin. Alaken Inc., Fort Collins, CO, USA, pp. 203212.

Scott, P.M., 1989. Methods for determination of aflatoxin M1 in milk and milk products - a review of performance characteristics. Food Addit Contam. 6 (3), 283-305.

Scott, P.M., 1995. Mycotoxin methodology. Food Addit. Contam. 12 (3), 395-403.

Sydenham, E.W., Shephard, G.S., 1996. In: Gilbert, J. (Ed.), Progress in Food Contamination Analysis. Blackie Accademic and Professional, London, UK.

van Egmond, H.P., Wagstaffe, P.J., 1992. Commission of European Communities, bcr information-reference materials. Report EUR 10412 EN, Belgium.

Vasilikotis, G.S., Papadoyannis, I.N., 1985. A simple method for the fluoridensitometric determination of aflatoxin M1 in milk powder. Microchem. J. 31, 170-172.

Warwick, M.J., 1996. Cap 8. Standardisation of immunoassay. In: Brian, L. (Ed.), Immunoassay, A Practical Guide. Taylor \& Francis Ltd., London, UK, p. 160. 